\title{
Long-Term Weight-Loss Maintenance by a Meal Replacement Based Weight Management Program in Primary Care
}

\author{
Renate Kruschitz ${ }^{a, b}$ Sandra Wallner-Liebmann ${ }^{c}$ Harald Lothaller ${ }^{d}$ \\ Maria Luger ${ }^{a}$ e Bernhard Ludvik ${ }^{b}$ \\ a Medical University Vienna, Clinic for Internal Medicine III, Department of Endocrinology \& \\ Metabolism, Vienna, Austria; ${ }^{b}$ Department of Medicine I with Diabetology, Endocrinology \\ and Nephrology and Karl Landsteiner Institute for Obesity and Metabolic Diseases, \\ Rudolfstiftung Hospital, Vienna, Austria; ' Institute of Pathophysiology and Immunology, \\ Medical University Graz, Graz, Austria; ${ }^{d}$ statistik@ lothaller.net, Graz, Austria; ${ }^{\text {SIPCAN }}$ \\ Special Institute for Preventive Cardiology And Nutrition, Elsbethen/Salzburg, Austria
}

\section{Key Words}

Long-term weight loss maintenance $\cdot$ Primary care $\cdot$ Body composition $\cdot$ Meal replacement

\begin{abstract}
Objective: Structured obesity treatment programs at primary care level are becoming increasingly important. However, evidence from current treatment approaches in the long term is lacking. In view of this fact we evaluated a standardized, meal replacement-based weight loss program (myLINE ${ }^{\circledR}$; AENGUS, Graz, Austria) according to the currently applicable guidelines. Methods: Data of overweight and obese individuals $(n=70)$ who participated at least 36 months in the program were analyzed. Data were collected at baseline (T0) as well as after $1,3,6,12,24$, and 36 (T1-T36) months. Body composition was measured by conventional anthropometry and bioelectrical impedance analysis. Results: Compared to T0, a maximum weight, BMI, fat mass, absolute body cell mass (BCM) reduction and an increase of relative $\mathrm{BCM}$ could be seen at T6. Subsequently, the findings reveal a significant reduction of body weight and body fat and a satisfying development of body cell mass during the observation period of 36 months. Conclusion: The evaluated program complies with national and international guidelines for the therapy of obesity in adults and is efficient and meaningful for a long-term therapeutic use in primary care..

c) 2017 The Author(s)

Published by S. Karger GmbH, Freiburg
\end{abstract}




\section{Introduction}

The latest Austrian Nutrition Report has shown a prevalence of overweight and obesity among adults of nearly $40 \%$. Overweight is one of the most common health issues in Austria, as in many other European Countries [1,2].

From a health care perspective, addressing overweight and obesity is an important strategy in the primary and secondary prevention as high body weight and body fat are associated with an increased risk of cardiovascular complications, certain cancers, diabetes mellitus type 2, Alzheimer's disease, gallbladder disease, sleep apnea, osteoarthritis, renal disease, and musculoskeletal disorders [2-5]. A modest weight loss of 5-10\% has been shown to reduce the risk of developing diabetes by $58 \%$ in at-risk patients [6] and diminishes the overall risk of mortality by $20 \%$ [7-9]. Effective weight reduction can decrease disease risk, lower health service expenditure, and improve the quality of life of affected persons [10-12]. Studies have shown that structured treatment programs with regular follow-up are able to improve long-term weight loss and maintenance [13, 14]. Such programs, especially at primary care level, are becoming increasingly important to overcome the rising demand of treatment options in context with the constantly growing numbers of obese individuals. However, evidence in the long term ( $>24$ months) from current treatment approaches is lacking. Many products and related plans are appearing on the market with little evidence of their tolerance and weight loss-promoting effectiveness [15].

Therefore, we hypothesized that participants of a standardized, meal replacement-based weight loss program can achieve clinically relevant weight loss and weight maintenance over a period of 36 months. For this purpose, we evaluated 36-month anthropometric data of a standardized, meal replacement-based weight loss program conducted in Austrian primary care units according to the currently applicable guidelines for the management of obesity in adults to provide additional information about realistic long-term outcomes for health professionals and patients.

The aim of this study was to prove our hypothesis that participants of a standardized, meal replacement-based weight loss program can achieve clinically relevant initial weight loss and weight maintenance over a period of 36 months.

\section{Material and Methods}

\section{Subjects}

Out of a random sample of 1,237 overweight and obese participants, those individuals who attended the program at least 36 months and have complete data at all evaluated time points (baseline (T0), 1, 3, 6, 12, 24 and 36 (T1-T36) month(s)), were analyzed, leaving a sample of 70 participants. Exclusion criteria were BMI $<25 \mathrm{~kg} / \mathrm{m}^{2}$, diabetes mellitus, being pregnant or lactating, cardiovascular disease, other medical conditions contraindicating weight loss, substance abuse, severe psychiatric illness, and eating disorders (anorexia nervosa, bulimia nervosa, binge eating disorder). The procedures used in this evaluation were in accordance with the Declaration of Helsinki in the currently valid version amended by the 64th WMA General Assembly, Fortaleza, Brazil, October 2013, and were approved and registered (No 2107/2013) by the Ethics Committee of the Medical University of Vienna. All participants gave their written informed consent prior to their inclusion into the program.

Program Design

The myLINE ${ }^{\circledR}$ program (AENGUS, Graz, Austria) (www.myline.at) is a standardized, meal replacementbased weight loss program with a duration of at least 24 weeks. The diet is in accordance with the latest nutritional recommendations of the German Nutrition Society (Deutsche Gesellschaft für Ernährung; DGE), the Austrian Nutrition Society (Österreichische Gesellschaft für Ernährung; ÖGE), the Swiss Nutrition Society 
Kruschitz et al.: Long-Term Weight-Loss Maintenance by a Meal Replacement Based Weight Management Program in Primary Care

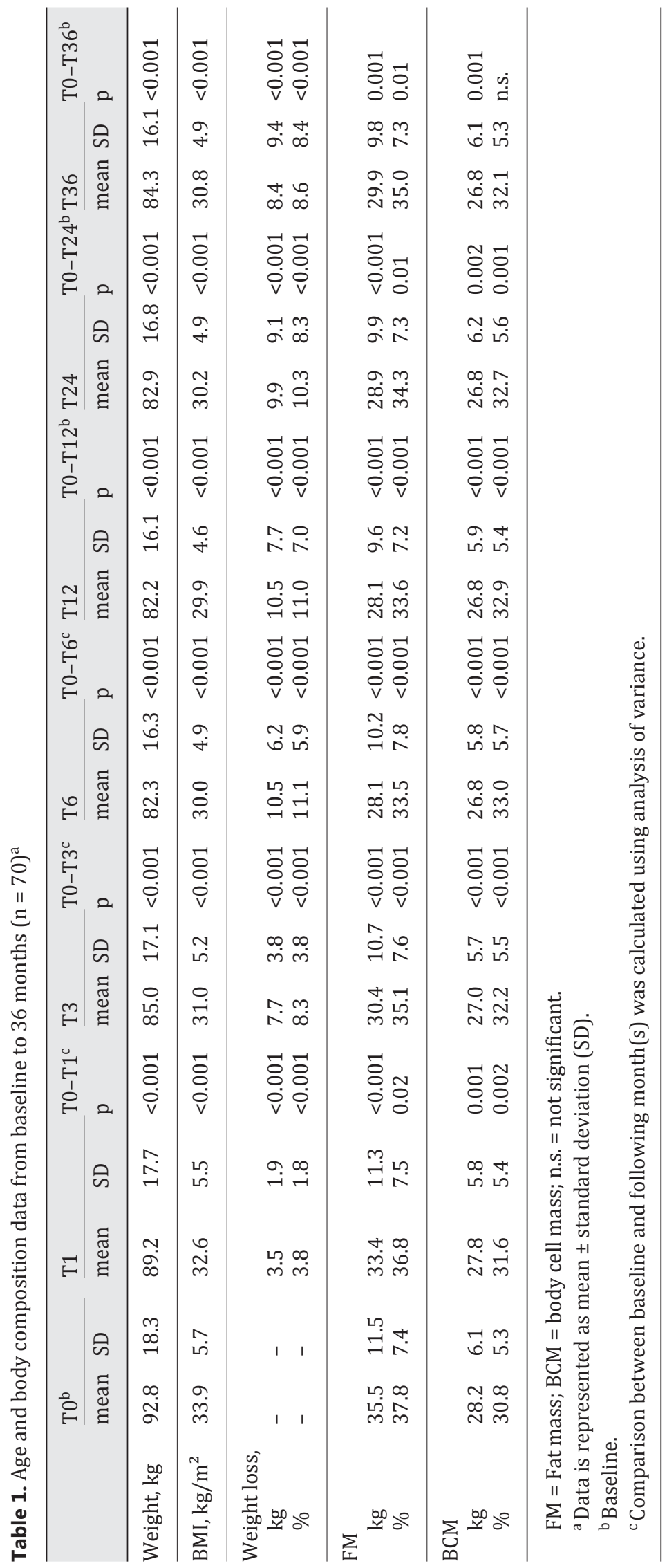


Kruschitz et al.: Long-Term Weight-Loss Maintenance by a Meal Replacement Based Weight Management Program in Primary Care

(Schweizerische Gesellschaft für Ernährung; SGE), and the Swiss Association for Nutrition (Schweizerische Vereinigung für Ernährung; SVE) which are called D-A-CH-recommendations [16].

The program consists of four phases [17] starting with a very low calorie diet (VLCD) for 2 days, followed by an energy-reduced diet consisting of meal replacements two times or once per day and one or two fat reduced meal(s) until the participant achieves two-thirds of the intended weight reduction, but at least for 10 weeks. Afterwards, the participants should maintain their weight without meal replacements. The regular follow-up intervals of the program are as follows: start, reduction, and transition phase - weekly or every 14 days; stabilization phase - once a month; afterwards - four times a year. During the whole program, the participants were measured at the regular visits by bioelectrical impedance analysis (BIA) and conventional anthropometry and received individual nutritional advice from a registered dietician. Within individual faceto-face consultations, aims and treatment plans, including improvement of the activity level in accordance with the actual recommendations, are defined. A nutrition and activity diary for self-reflection and a participant handbook for support and exercises at home are used as instruments of behavior therapy. After the weight reduction, there is the possibility to participate in a follow-up program for an unlimited period of time.

\section{Meal Replacement}

The declaration of all products took place at the Austrian Federal Ministry of Health as foods intended for use in energy-restricted diets for weight reduction. All products are in accordance to the directive 96/8/ EG European dietetic food regulation. Furthermore, products undergo regular laboratory controls and are only available in primary care units in combination with regular follow-up examinations [18].

\section{Body Composition}

The measurement of body composition was performed by conventional anthropometry (weight, height, waist circumference) and BIA (AKERN BIA $101^{\mathrm{TM}}$ (SMT medical GmbH \& Co. KG, Würzburg, Germany), BIACORPUS RX 4000 TM (MEDI CAL HealthCare GmbH, Karlsruhe, Germany), Software BodyComposition V 8.4 Professional (MEDI CAL HealthCare GmbH)).

\section{Statistics}

Statistical analysis was performed by SPSS for Windows Version 20.0 (IBM Corporation, Armonk, New York, USA). All results are presented as mean and standard deviation (SD). Differences in the distribution of variables between time points as well as between men and women were tested by Student's t-test for two independent samples (in case of normally distributed variables) and by Mann-Whitney U-test (if variables were not normally distributed). We used repeated-measures analysis of variance (ANOVA), using random error (general linear model) to assess the effect of changes in anthropometric parameters between the sexes. Moreover, a post-hoc analysis with Bonferroni correction was applied. Linear regression was used to identify independent variables, e.g., age, gender, initial BMI, body cell mass (BCM), associated with differences in weight loss. Binary logistic regression was used to estimate the odds for influence of initial BMI on weight loss. P values $<0.05$ were considered significant.

\section{Results}

Female individuals covered $81 \%$ of the population. The mean age was $54 \pm 14$ years. The baseline characteristics are presented in table 1 . In comparison to their female counterparts, men showed higher weight, BMI, BCM (all p < 0.001) and lower fat mass (FM) (p < 0.001) at T0. These differences remained constant over the whole observation period, indicating that there are no significant differences in the development of weight, FM and BCM between the sexes over time (see fig. 2 as an example), but female participants showed lower weight and $\mathrm{BCM}$ and a higher FM compared to men.

The greatest mean reduction of absolute and relative weight (T0-T6: $10.5 \pm 6.2 \mathrm{~kg}, \mathrm{p}<$ $0.001 ; 11.1 \pm 5.9 \%, \mathrm{p}<0.001$ ), BMI, FM, and absolute BCM could be observed at T6 (fig. 1, table 1). Moreover, a maximum increase of relative BCM could be seen at T6 (table 1).

All evaluated parameters remained stable until T12. Out of the original sample ( $\mathrm{n}=$ 1,237), those who attended the program at least 12 months $(n=1,167)$ showed a lower 
Kruschitz et al.: Long-Term Weight-Loss Maintenance by a Meal Replacement Based Weight Management Program in Primary Care

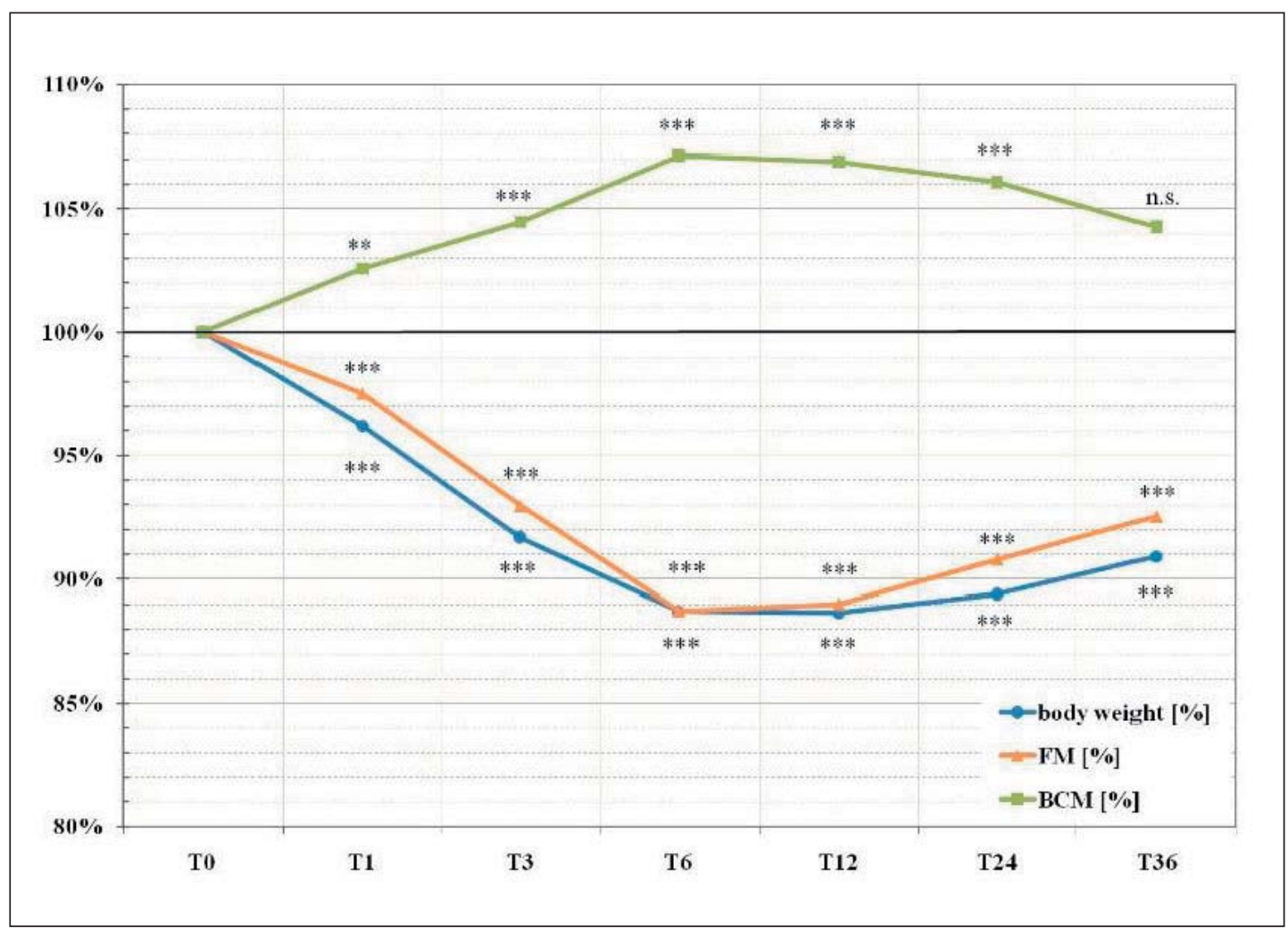

Fig. 1. Representing relative body weight, FM and BCM development from baseline (T0) (= 100\%) to 36 months (mean \pm SD). ${ }^{* * *}$ p $<0.001$, n.s. = not significant.

weight loss at T12 in comparison with participants attending at least 36 months $(n=70)(8.6$ $\pm 7.5 \mathrm{~kg}$ vs. $10.5 \pm 7.7 \mathrm{~kg}, \mathrm{p}<0.05 ; 8.2 \pm 7.8 \%$ vs. $11.0 \pm 7.0 \%, \mathrm{p}=0.01)$. At T12, $61 \%$ of all participants achieved a minimal weight loss of $5 \%, 36 \%$ of $10 \%$, and $19 \%$ of more than $15 \%$ of their initial weight, which is comparable with the previously published data of the 12-month sample [17]. A slight weight and FM increase and a BCM decrease was seen at the subsequent 24- and 36-month follow-ups. Nevertheless, at T24 and T36, weight and FM were significantly lower and absolute BCM significantly higher compared to T0. At T36, relative BCM was not longer significantly higher compared to T0 (fig. 1).

By using a multivariate linear regression model with weight loss as independent variable (difference of weight in $\mathrm{kg}$ at T36 and at T0) and sex, age, initial BMI, and initial BCM as dependent variable, only initial BMI showed a significant negative association $(\beta=-0.501$; $\mathrm{p}<0.001$ ). Moreover, participants with an initial BMI $\leq 35 \mathrm{~kg} / \mathrm{m}^{2}$ had a higher chance of greater weight loss at T3 and T24 (T3: OR 1.70, 95\%CI 1.09-2.67; $\mathrm{p}=0.02$; T24: OR 1.33; 95\%CI 1.06-1.66; $\mathrm{p}=0.02$ ), but not at T12 (OR 0.56; 95\%CI 0.38-0.82; $<<0.01$ ).

\section{Discussion}

Successful weight maintenance after weight reduction is the greatest challenge in the therapy of obesity. Effective methods to achieve this ambitious goal, especially in primary care, are required $[19,20]$. In this study, the long-term success of a meal replacement-based weight management program in adults with respect to changes in body weight and body 
Kruschitz et al.: Long-Term Weight-Loss Maintenance by a Meal Replacement Based Weight Management Program in Primary Care

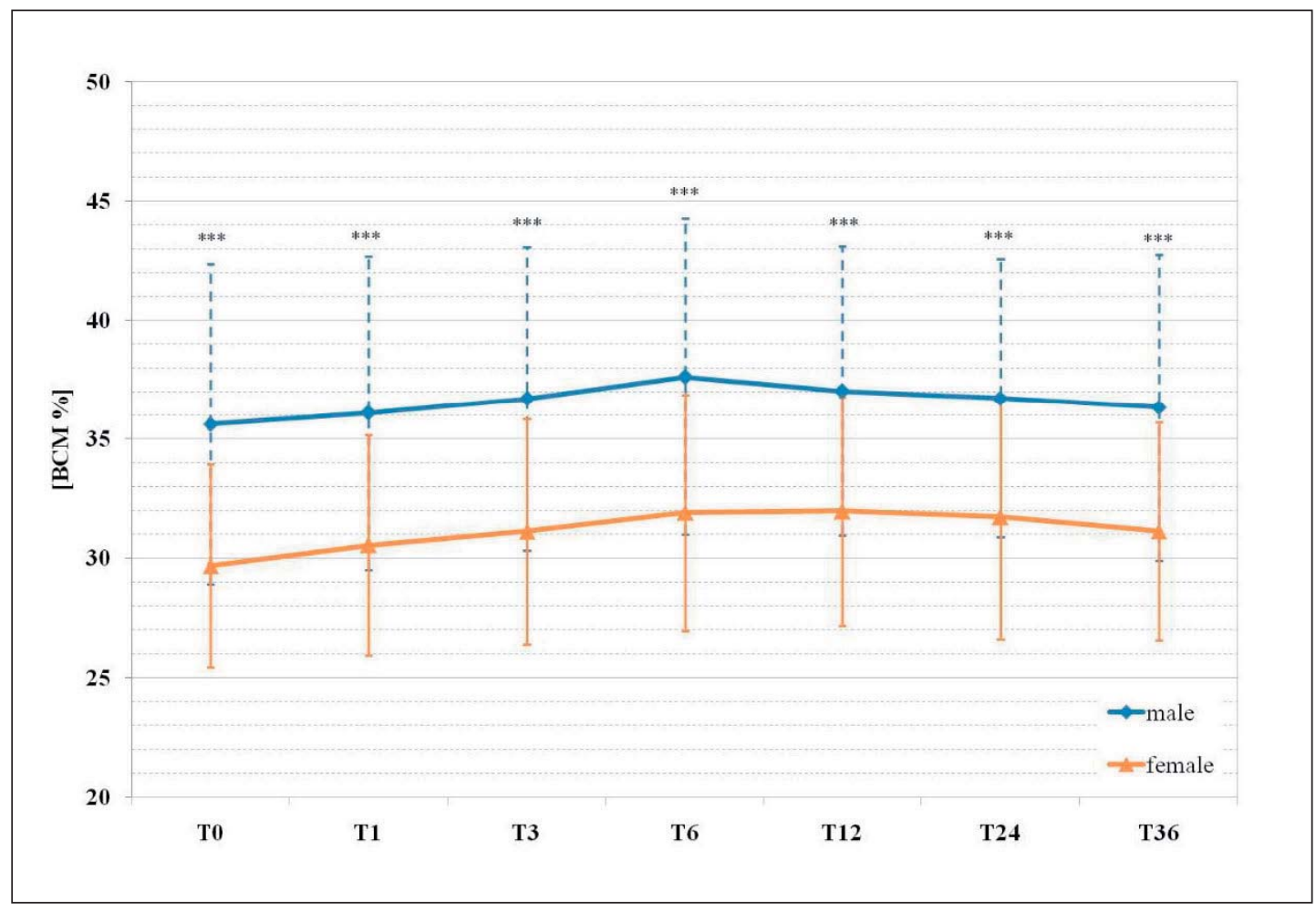

Fig. 2. Representing relative BCM development in males and females from baseline (T0) to 36 months (T36) $($ mean $\pm \mathrm{SD}) . * * * \mathrm{p}<0.001$.

composition was analyzed. As defined by the European guidelines, a weight reduction of $5-15 \%$ within 6 months or of $0.5-1.0 \mathrm{~kg} /$ week are realistic and desirable [2, 21]. International committees consider a weight reduction of $5-10 \%$ of the initial body weight as adequate to reduce the health risk in obese patients and, moreover, to prevent excess weight gain [19, 21]. Additionally, Hauner et al. [22] defined success for obesity therapy programs in primary care as follows: at least $50 \%$ of the participants have to lose $5 \%$ of their initial weight, and $20 \%$ should achieve a weight reduction of $10 \%$ from baseline. For the definition of long-term success, no uniform definition exists. The Institute of Medicine defined long-term success as an achieved body weight at least $5 \%$ below the initial weight or BMI at least one unit below the baseline BMI 1 year after weight reduction [23]. Furthermore, Wing and Hill [24] proposed that successful weight loss maintainers are defined as patients that initially have lost at least $10 \%$ of their body weight and stabilized at least for 1 year. Regarding weight maintenance, the Clinical Guidelines on Evaluation and Treatment of Overweight and Obesity in Adults have defined successful weight maintenance after weight loss as a weight regain of less than $3 \mathrm{~kg}$ in 2 years [25].

In regard to the evaluated program, the average weight reduction was $11 \mathrm{~kg}$ and $11 \%$ after 6 months. Compared to the data of Franz et al. [26], who systematically reviewed the long-term effect of 80 different weight loss interventions, the present data are within or even above the reported range, especially in comparison with trials using meal replacements. Franz et al. [26] concluded that weight loss tends to reach a plateau, ranging between 5.0 and $8.5 \mathrm{~kg}$ (5-9\% of initial body weight) after 6 months of treatment, gradually decreasing to $3.0-5.0 \mathrm{~kg}$ (3-6\% of initial body weight) after 48 months [26]. In the current study, more than $60 \%$ of the participants reached a weight reduction of minimum $5 \%$ and more than one-third 
Kruschitz et al.: Long-Term Weight-Loss Maintenance by a Meal Replacement Based Weight Management Program in Primary Care

a reduction of minimum $10 \%$ of their initial body weight. Moreover, compared to BMI at the beginning of the program, BMI after 12 and 36 months was on average 4 and 3 units lower, respectively. These results are in accordance with the above referred criteria. Additionally, long-term weight loss was greater than observed in other primary care trials [27-30], with the exception of a study involving morbidly obese patients who were treated with intensive group lifestyle modification and weight loss medications [31]. Reduction in body fat and preservation of lean body mass is crucial for beneficial metabolic effects, prevention of weight regain, and sarcopenic obesity due to loss of BCM [19,32]. White adipose tissue is recognized as an active endocrine tissue that secretes numerous immunomodulatory factors which play major roles in the regulation of human metabolic and vascular biology and is therefore significantly involved in the pathogenesis of the metabolic syndrome [33]. To significantly reduce the metabolic risk associated with endocrine active adipose tissue, it is necessary to reduce and maintain weight over a period of 3 years [34]. The collected data showed a body fat reduction of $11 \%$ at $\mathrm{T} 6$ and $8 \%$ at $\mathrm{T} 36$, which might suggest a metabolically effective weight reduction. In order to verify this effect, an additional analysis of laboratory parameters would be expedient. However, the measurement of body composition during weight reduction seems to be indisputable. In the present study, the routine measurement with the BIA appears as informative and beneficial. Results from dual energy X-ray absorptiometry would be more accurate but are not practicable and too expensive in primary care. During the observation period, the absolute BCM decreased although the relative BCM increased. This indicates a satisfactory overall development of muscle mass despite of weight reduction.

Interestingly, using a multivariate linear regression model and a logistic regression, we found that initial BMI influenced weight loss over the time period of 36 months. The other dependent variables, such as age, sex or initial BCM, showed no significant correlation with weight loss. Moreover, the results of the logistic regression strengthened the influence of initial BMI on weight loss as lower BMI at baseline showed a higher chance of greater weight loss in the short (T3) and in the long term (T24) but not in the medium term (T12). Possible explanations for the success of the examined weight management program might be the intensive patient contact, the individual dietary counseling, and the guidance for physical activity as well as the standardized optimal nutrient intake which are factors that were seen as preventive for weight regain $[13,14,35,36]$. One essential component of the program is a long-term modification of dietary and physical activity habits. The program supports the participant during and after the weight reduction with behavioral interventions: i) a nutritional and physical activity diary for patient self-monitoring, ii) the participant handbook as basis for the therapeutic one-on-one counseling, iii) and the group meetings as a communication platform for participants and for increasing their nutritional knowledge. In further studies the quality of participant's contact and satisfaction in this program was evaluated [18, 37-39] and therefore the program corresponds also to the requirements of regular quality checks of obesity programs in primary care [22].

Limitations of the current report are the small sample size due to the restricted availability of complete 36-month data and the absence of an adequate control group. Nevertheless, this sample is well characterized and the anthropometric data are complete, which strengthens our study. Due to the analysis of complete 36-month data, the possibility of a selection bias exists and therefore the results may be biased towards an over-positive assessment of effectiveness. Nevertheless, the data are novel because to date and to our current knowledge no study has assessed 36-month anthropometric data of a meal replacement-based weight management program in primary care. 
Kruschitz et al.: Long-Term Weight-Loss Maintenance by a Meal Replacement Based Weight Management Program in Primary Care

\section{Conclusion}

This data shows clinical relevant initial weight loss and maintenance over a period of 36 months in participants of a standardized, meal replacement-based weight loss program. The evaluated program complies with national and international guidelines for the therapy of obesity in adults and is efficient and meaningful for a long-term therapeutic use in primary care. The results emphasize the importance of regular body composition measurements during weight reduction and weight maintenance. The findings reveal a significant reduction of body weight and body fat as well as a satisfying development of BCM during the observation period of 36 months. Nevertheless, during the observation period, a turning point was observed at T12 after 6 months stabilization. Accordingly, after 12 months, participants started slightly to regain weight and FM and to lose BCM. Based on these findings, we can assume that once the weight reduction has been terminated it is of great importance for patients and health professionals to stay motivated beyond the classical observation period of 12 months, especially in those patients with initial BMI $>35 \mathrm{~kg} / \mathrm{m}^{2}$. This means regular controls with conventional anthropometry, body composition measurements, dietary advice, and also behavior-therapeutic tools to support participants also after weight reduction. Further studies with an observation period of more than 24 months in consideration of metabolic parameters are needed to examine the long-term weight development and the metabolic effect of such weight management programs.

\section{Disclosure Statement}

Sandra Wallner-Liebmann and Bernhard Ludvik are members of the myLINE ${ }^{\circledR}$ scientific advisory board without remuneration. Maria Luger has no conflicts of interest and fundings to declare. Harald Lothaller and Renate Kruschitz have received funding from AENGUS for data processing. The authors do not have any commercial interest in the subject of the study.

\section{References}

1 Elmadfa I, Freisling H, Nowak V, Hofstädter D: Österreichischer Ernährungsbericht 2012. Wien, BundesministeriumfürGesundheit,2012.www.bmgf.gv.at/cms/home/attachments/4/5/3/CH1048/CMS1348749794860/ oeb12.pdf (last accessed March 22, 2017).

2 Yumuk V, Tsigos C, Fried M, Schindler K, Busetto L, Micic D, Toplak H: European guidelines for obesity management in adults. Obes Facts 2015;8:402-424.

3 Meyer H, Sogaard A, Tverdal A, Selmer R: Body mass index and mortality: the influence of physical activity and smoking. Med Sci Sports Exerc 2002;34:1065-1070.

4 Must A, Spadano J, Coakley EH, Field AE, Colditz G, Dietz WH: The disease burden associated with overweight and obesity. JAMA 1999;282:1523-1529.

5 Frühbeck G, Toplak H, Woodward E, Yumuk V, Maislos M, Oppert JM: Obesity: the gateway to ill health - an EASO position statement on a rising public health, clinical and scientific challenge in Europe Obes Facts 2013; 6:117-120.

6 Tuomilehto J, Lindstrom J, Eriksson J, Valla T, Hamalainen H, Ilanne-Parikka P, Keinanen-Kiukaanniemi S, Laakso M, Louheranta A, Rastas M, Salminen V, Unsitupa M: Prevention of type 2 diabetes mellitus by changes in lifestyle among subjects with impaired glucose tolerance. N Engl J Med 2001;344:1343-1349.

7 Williamson D, Thompson T, Thun M, Flanders D, Pamuk E, Byers T: Intentional weight loss and mortality among overweight individuals with diabetes. Diabetes Care 2000;23:1499-1504.

8 Williamson D, Pamuk E, Thun M, Flanders D, Byers T, Heath C: Modest intentional weight loss increases life expectancy in overweight women. Am J Epidemiol. 1995;141:1128-1141.

9 Lean M, Powrie J, Anderson A, Garthwaite P: Obesity, weight loss and prognosis in type 2 diabetes. Diabet Med 1990;7:228-233.

10 Laws R, Reckless J, on behalf of the Counterweight Project Team: Differences in disease prevalence between obese and normal weight individuals. Int J Obes 2003;27(suppl 1):S83.

11 de Zwaan M, Petersen I, Kaerber M, Burgmer R, Nolting B, Legenbauer T, Benecke A, Herpertz S: Obesity and quality of life: a controlled study of normal-weight and obese individuals. Psychosomatics 2009;50:474-482. 
Kruschitz et al.: Long-Term Weight-Loss Maintenance by a Meal Replacement Based Weight Management Program in Primary Care

12 Bachmann KH: Obesity, weight management, and health care costs: a primer. Dis Manag 2007;10:129-137.

13 Moyer VA; U.S. Preventive Services Task Force: Screening for and management of obesity in adults: U.S. Preventive Services Task Force Recommendation Statement. Ann Intern Med 2012;157:373-378.

14 Wadden TA, Neiberg RH, Wing RR, Clark JM, Delahanty LM, Hill JO, Krakoff J, Otto A, Ryan DH, Vitolins MZ: Four-year weight losses in the Look AHEAD Study: factors associated with long-term success. Obesity (Silver Spring) 2011;19:1987-1998.

15 Heymsfield SB, van Mierlo CAJ, van der Knaap HCM, Heo M, Frier HI: Weight management using a meal replacement strategy: meta and pooling analysis from six studies. Int J Obes 2003;27:537-549.

16 Deutsche Gesellschaft für Ernährung Österreichische Gesellschaft für Ernährung, Schweizerische Gesellschaft für Ernährungsforschung, Schweizerische Vereinigung für Ernährung: D-A-CH Referenzwerte für die Nährstoffzufuhr, 2. Auflage. Bonn, 2015.

17 Kruschitz R, Wallner-Liebmann SJ, Lothaller H, Luger M, Schindler K, Hoppichler F, Ludvik B: Evaluation of a meal replacement-based weight management program in primary care settings according to the actual European Clinical Practice Guidelines for the Management of Obesity in Adults. Wien Klin Wochenschr 2014; 126:598-603.

18 Wallner S, Wascher T: Qualitätsanalyse von Adipositasprogrammen am Beispiel von myLINE-Ernährung und Bewegung, einer Adipositas-Therapie beim niedergelassenen Arzt. J Ernährungsmed 2006;8:11-16.

19 Frühbeck G, Toplak H, Woodward E, Halford JCG, Yumuk V: Need for a paradigm shift in adult overweight and obesity management - an EASO position statement on a pressing public health, clinical and scientific challenge in Europe. Obes Facts 2014;7:408-416

20 Kassirer J, Angell M. Losing weight - an ill-fated new year's resolution. N Engl J Med 1998;338:52-54.

21 Tsigos C, Hainer V, Basdevant A, Finer N, Fried M, Mathus-Vliegen E, Micic D, Maislos M, Roman G, Schutz Y, Toplak H, Zahorska-Markiewicz B: Management of obesity in adults: European Clinical Practice Guidelines. Obes Facts 2008;1:106-116.

22 Hauner H, Wechsler J, Kluthe R, Liebermeister H, Erbersdobler H, Wolfram G, FürstP, Jauch K: Qualitätskriterien für ambulante Adipositasprogramme. Aktuel Ernahrungsmed 2000;25:163-165.

23 Thomas P (ed): Weighing the Options: Criteria for Evaluating Weight-Management Programs. Washington, National Academic Press, 1995.

24 Wing R, Hill J: Successful weight loss maintenance. Annu Rev Nutr. 2001;21:323-341.

25 Stevens J, Truesdale K, McClain J, Cai J: The definition of weight maintenance. Int J Obes 2006;30:391-399.

26 Franz MJ, VanWormer JJ, Lauren Crain A, Boucher JL, Histon T, Caplan W, Bowman JD, Pronk NP: Weight-loss outcomes: a systematic review and meta-analysis of weight-loss clinical trials with a minimum 1-year followup. J Am Diet Assoc 2007;107:1755-1767.

27 Christian JG, Bessesen DH, Byers TE, Christian KK, Goldstein MG, Bock BC: Clinic-based support to help overweight patients with type 2 diabetes increase physical activity and lose weight. Arch Intern Med 2008;168:141-146.

28 Jebb SA, Ahern AL, Olson AD, Aston LM, Holzapfel C, Stoll J, Amann-Gassner U, Simpson AE, Fuller NR, Pearson S, Lau NS, Mander AP, Hauner H, Caterson ID: Primary care referral to a commercial provider for weight loss treatment versus standard care: a randomised controlled trial. Lancet 2011;378:1485-1492.

29 Kumanyika S, Fassbender J, Sarwer D, Phipps E, KAllison K, Localio R, Knashawn H, Wesby L, Harralson T, Kessler R, Tan-Torres S, Han X, Tsai A, Wadden T: One-year results of the think health! study of weight management in primary care practices. Obesity (Silver Spring) 2012;20:1249-1257.

30 Martin P, Dutton G, Rhode P, Horswell R, Ryan D, Brantly P: Weight loss maintenance following a primary care intervention for low-income minority women. Obesity (Silver Spring) 2008;16:2462-2467.

31 Ryan D, Johnson W, Myers V, Prather TL, McGlone MM, Rood J, Brantley PJ, Bray GA, Gupta AK, Broussard AP, Barootes BG, Elkins BL, Gaudin DE, Savory RL, Brock RD, Datz G, Pothakamuri SR, McKnight GT, Stenlof K, Sjöström LV: Nonsurgical weight loss for exteme obesity in primary care settings: results of the Louisiana Obese Subjects Study. Arch Intern Med 2010;170:146-154.

32 Santarpia L, Contaldo F, Pasanisi F. Body composition changes after weight-loss interventions for overweight and obesity. Clin Nutr 2013;32:157-161.

33 Hutley L, Prins J: Fat as an Endocrine organ: relationship to the metabolic syndrome. Am J Med Sci 2005;330: 280-289.

34 Madsen El, Rissanen A, Bruun JM, Skogstrand K, Tonstad S, Hougaard DM, Richelson B: Weight loss larger than $10 \%$ is needed for general improvement of levels of circulating adiponectin and markers of inflammation in obese subjects; a 3-year weight loss study. Eur J Endocrinol 2008;58:179-187.

35 Ross Middleton KM, Patidar SM, Perri MG: The impact of extended care on the long-term maintenance of weight loss: a systematic review and meta-analysis. Obes Rev 2012;13:509-517.

36 Thomas JG, Wing RR: Maintenance of long-term weight loss. Med Health R I. 2009;92:56-57. www.rimed.org/ medhealthri/2009-02/2009-02-53.pdf (last accessed March 22, 2017).

37 Wallner S, Piccoli A, Lothaller H, Liebmann P, Schnedl W, Schaunstein K: Body composition changes during a program for fat loss in obesity. Evaluation with conventional and vector bioelectrical analysis. Obes Rev 2006; $7($ suppl 2):178.

38 Kruschitz R, Lothaller H, Wascher T, Liebmann P, Schnedl W, Wallner S. Evaluation of Weight-Management Programs and the impact of the return ration of questioning. Aktuel Ernahrungsmed 2007;3:137-146.

39 Kruschitz R, Lothaller H, Liebmann P, Schnedl W, Wallner S: Successful weight maintenance and body composition: a 6 to 30 months follow-up. Int J Obes 2008;32(suppl 1):S119. 